University of Nebraska - Lincoln

DigitalCommons@University of Nebraska - Lincoln

USDA National Wildlife Research Center - Staff Publications
U.S. Department of Agriculture: Animal and Plant Health Inspection Service

2009

\title{
Landscape-Genetic Analysis of Population Structure in the Texas Gray Fox Oral Rabies Vaccination Zone
}

\author{
Randy DeYoung \\ Texas A\&M University-Kingsville, Caesar Kleberg Wildlife Research Institute, randall.deyoung@tamuk.edu \\ Angeline Zamorano \\ Texas A\&M University-Kingsville, Caesar Kleberg Wildlife Research Institute \\ Brian Mesenrink \\ USDA-APHIS-Wildlife Services \\ Tyler A. Campbell \\ USDA/APHIS/WS National Wildlife Research Center, tcampbell@eastfoundation.net \\ Bruce Leland \\ USDA-APHIS-Wildlife Services \\ See next page for additional authors
}

Follow this and additional works at: https://digitalcommons.unl.edu/icwdm_usdanwrc

Part of the Environmental Sciences Commons

DeYoung, Randy; Zamorano, Angeline; Mesenrink, Brian; Campbell, Tyler A.; Leland, Bruce; Moore, Guy; Honeycutt, Rodney; and Root, J. Jeffrey, "Landscape-Genetic Analysis of Population Structure in the Texas Gray Fox Oral Rabies Vaccination Zone" (2009). USDA National Wildlife Research Center - Staff

Publications. 908.

https://digitalcommons.unl.edu/icwdm_usdanwrc/908

This Article is brought to you for free and open access by the U.S. Department of Agriculture: Animal and Plant Health Inspection Service at DigitalCommons@University of Nebraska - Lincoln. It has been accepted for inclusion in USDA National Wildlife Research Center - Staff Publications by an authorized administrator of DigitalCommons@University of Nebraska - Lincoln. 


\section{Authors}

Randy DeYoung, Angeline Zamorano, Brian Mesenrink, Tyler A. Campbell, Bruce Leland, Guy Moore, Rodney Honeycutt, and J. Jeffrey Root 


\title{
Landscape-Genetic Analysis of Population Structure in the Texas Gray Fox Oral Rabies Vaccination Zone
}

\author{
RANDY W. DEYOUNG, ${ }^{\mathbf{1}}$ Caesar Kleberg Wildife Research Institute, Texas AछMM University-Kingsville, Kingsville, TX 78363, USA \\ ANGELINE ZAMORANO, Caesar Kleberg Wildlife Research Institute, Texas AङM University-Kingsville, Kingsville, TX 78363, USA \\ BRIAN T. MESENBRINK, United States Department of Agriculture, Wildlife Services, National Wildlife Research Center, Kerrville, TX 78028, USA \\ TYLER A. CAMPBELL, United States Department of Agriculture, Wildlife Services, National Wildlife Research Center, Kingsville Field Station, \\ Kingsville, TX 78363, USA \\ BRUCE R. LELAND, United States Department of Agriculture, Wildlife Services, San Antonio, TX 78201, USA \\ GUY M. MOORE, Texas Department of State Health Services, Austin, TX 78756, USA \\ RODNEY L. HONEYCUTT, Pepperdine University, Natural Science Division, 24255 Pacific Coast Highway, Malibu, CA 90263, USA \\ J. JEFFREY ROOT, United States Department of Agriculture, Wildlife Services, National Wildlife Research Center, Fort Collins, CO 80521 , USA
}

\begin{abstract}
In west-central Texas, USA, abatement efforts for the gray fox (Urocyon cinereoargenteus) rabies epizootic illustrate the difficulties inherent in large-scale management of wildlife disease. The rabies epizootic has been managed through a cooperative oral rabies vaccination program (ORV) since 1996. Millions of edible baits containing a rabies vaccine have been distributed annually in a $16-\mathrm{km}$ to $24-\mathrm{km}$ zone around the perimeter of the epizootic, which encompasses a geographic area $>4 \times 10^{5} \mathrm{~km}^{2}$. The ORV program successfully halted expansion of the epizootic into metropolitan areas but has not achieved the ultimate goal of eradication. Rabies activity in gray fox continues to occur periodically outside the ORV zone, preventing ORV zone contraction and dissipation of the epizootic. We employed a landscape-genetic approach to assess gray fox population structure and dispersal in the affected area, with the aim of assisting rabies management efforts. No unique genetic clusters or population boundaries were detected. Instead, foxes were weakly structured over the entire region in an isolation by distance pattern. Local subpopulations appeared to be genetically non-independent over distances $>30 \mathrm{~km}$, implying that long-distance movements or dispersal may have been common in the region. We concluded that gray foxes in west-central Texas have a high potential for long-distance rabies virus trafficking. Thus, a $16-\mathrm{km}$ to $24-\mathrm{km}$ ORV zone may be too narrow to contain the fox rabies epizootic. Continued expansion of the ORV zone, although costly, may be critical to the long-term goal of eliminating the Texas fox rabies virus variant from the United States. (JOURNAL OF WILDLIFE MANAGEMENT 73(8):1292-1299; 2009)
\end{abstract}

DOI: $10.2193 / 2008-336$

KEY WORDS gray fox, landscape genetics, oral rabies vaccination, population structure, spatial autocorrelation, Urocyon cinereoargenteus.

The effective control and abatement of animal disease outbreaks is an emerging wildlife management problem that is expected to increase in coming decades with the rise in globalization, urban encroachment, and spread of invasive species (DeYoung 2007). The highly publicized recent occurrences of foot-and-mouth disease in the United Kingdom and chronic wasting disease and bovine tuberculosis in the United States underscore the difficulty of spatially extensive management. Although rabies receives less media attention, the occurrence and management of animal rabies poses a significant problem. Rabies is a worldwide public health threat, causing an estimated 30,000-50,000 human deaths (primarily in third world countries) each year, with many millions of dollars spent on treatment and prevention (Real et al. 2005). In the United States, animal rabies generally occurs in free-ranging species of mammals, often small carnivores and bats, where genetically distinct rabies strains are present in discrete geographical areas. For instance, approximately $92 \%$ of rabies cases in the United States during 2004 were in wild animals (Krebs et al. 2005). Rabies transmission in wild populations occurs primarily among conspecifics and within defined geographic regions; the rate of interspecific

\footnotetext{
${ }^{1}$ E-mail: randall.deyoung@tamuk.edu
}

infection is generally low. Once the virus becomes established, rabies outbreaks may achieve long-term persistence (e.g., several decades or more) within geographic regions (Real et al. 2005).

A case cluster of rabies in gray fox (Urocyon cinereoargenteus) in eastern Texas, USA, in 1946 signaled the beginning of a gray fox rabies epizootic (Texas fox rabies virus variant [TF]) in the state (Texas Department of Health 2003), and in 1988 a major epizootic was noted (Sidwa et al. 2005). By 1994, this epizootic, and a simultaneous epizootic in coyotes (Canis latrans) and domestic dogs in south Texas (domestic dog-coyote rabies virus variant $[\mathrm{DDC}])$, were declared as state health emergencies (United States Department of Agriculture [USDA] 2002). To combat the potential public health risks, oral rabies vaccination (ORV) programs were initiated for wildlife in southern Texas for the DDC variant in 1995 and in west-central Texas for the TF variant in 1996 (Sidwa et al. 2005), with the ultimate goal of eliminating these strains of rabies virus from the United States (USDA 2001). The ORV programs used a recombinant vacciniarabies vaccine (Raboral V-RG ${ }^{\circledR}$; Rhone Merieux, Inc., Athens, GA) developed for the oral vaccination of select wildlife species against rabies virus. The general vaccination strategy was to distribute edible baits containing the rabies vaccine, creating a geographic zone of vaccinated individuals 
at the perimeter of the epizootic (Sidwa et al. 2005). Animals consuming the baits become immunized and the enzootic is disrupted when a sufficient portion of the population is vaccinated (i.e., the herd immunity concept; Fox et al. 1995).

Overall, ORV programs have yielded exceptional success with the use of Raboral V-RG (Sidwa et al. 2005). For instance, the DDC variant was effectively eliminated from south Texas by 2003 (Sidwa et al. 2005). The gray fox ORV program was successful in halting expansion of the TF variant, but rabies activity in Texas gray foxes continued to occur over a large geographic expanse of west-central Texas (Texas Department of Health 2003, Sidwa et al. 2005). The gray fox ORV program attempted to halt the eastern and northward expansion of the virus toward metropolitan areas of central Texas (including San Antonio) and the large red fox (Vulpes vulpes) populations in eastern Texas by creating a $16-\mathrm{km}$ to $24-\mathrm{km}$ wide vaccination zone, which was adjusted annually depending on resource availability and distribution of positive individuals (Sidwa et al. 2005). It was hypothesized that this strategic ORV zone would eventually reduce and encircle the affected area, with the ultimate goal of eliminating the TF variant from the United States.

Each year since the inception of the program, $>1$ million ORV baits have been distributed over thousands of square kilometers in west-central Texas. In recent years, the gray fox ORV zone in Texas has been large, extending from the border of Mexico to west-central Texas (Fig. 1). To date, rabies abatement of the affected area has not been achieved, as demonstrated by the periodic detection of rabid animals outside, but near the perimeter of, the gray fox ORV zone during evaluations following several annual bait dispersal campaigns (e.g., 1999, 2002, 2004, 2007; G. Moore, Texas Department of State Health Services, unpublished). The disparate success of the coyote versus the fox ORV may be partly due to the extensive geographic area of the fox ORV and the difficulty in allocating sufficient resources to blanket the entire affected area. However, the geographic distribution of rabies-infected mammals in other regions of the United States appears to be influenced in part by terrain features that affect animal movements (Childs et al. 2000, 2001; Smith et al. 2002). Thus, ecological information on gray fox movements and population structure in west-central Texas could improve the success of the gray fox ORV program. Unfortunately, much information pertaining to general ecology of gray fox in westcentral Texas remains undetermined.

Gray foxes are distributed statewide in Texas (Schmidly 1994), though some have suggested that gray foxes may be restricted to habitats where they are not excluded through behavioral interactions with sympatric coyotes and bobcats (Lynx rufus; MacDonald and Sillero-Zubiri 2004). Gray foxes exist in family units composed of an adult pair and their juvenile offspring (Schmidly 1994); juveniles may remain in their natal range until January-February the following year (Trapp and Hallberg 1975). Gray foxes are social and the (presumably monogamous) adult pairs have been observed to travel together within their home ranges (Chamberlain and Leopold 2000). Tagging and telemetry

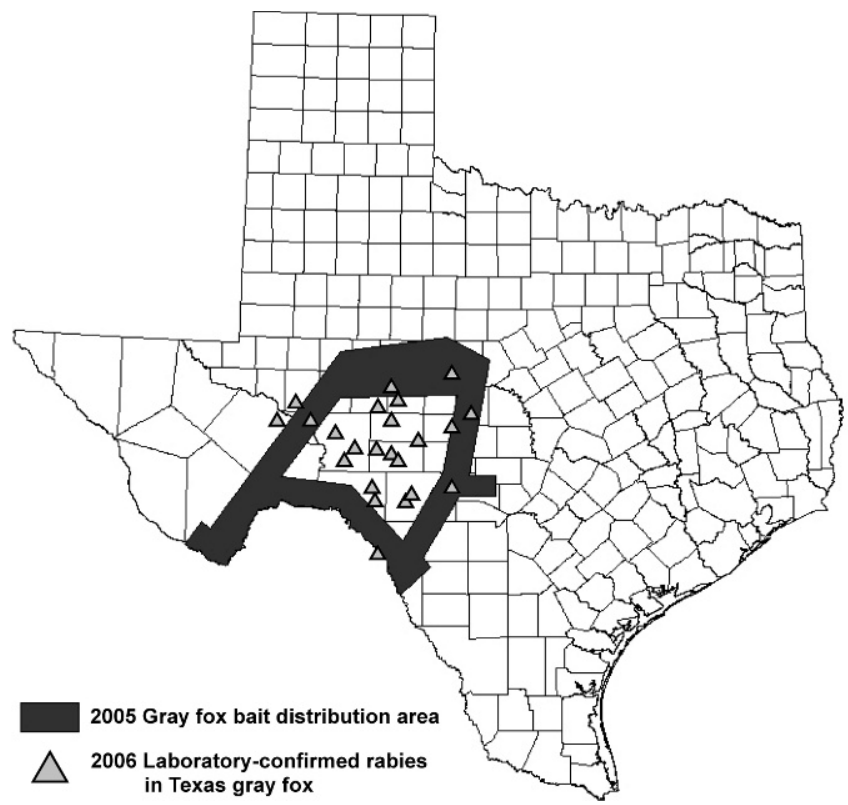

Figure 1. Oral rabies vaccination zone for gray fox in west-central Texas, USA, during 2005 and location of laboratory-confirmed cases of gray fox rabies in 2006. The zone and sample collection area encompassed all or parts of 33 counties.

studies have reported occasional long-distance movements (20-80 km; Sheldon 1953, B. Mesenbrink, USDA, Wildlife Services, National Wildlife Research Center, unpublished data), but the frequency, average distance, and the degree to which long-distance dispersers integrate into the population are unknown.

Information on the population structure and movement patterns of gray fox would allow for better use of the limited resources available for managing animal rabies in this geographically expansive area. Traditional wildlife studies, employing tagging and radiotelemetry, are informative but limited by expense and constraints on sample size. Recent advances in molecular techniques have made large-scale genetic analyses of wildlife populations feasible (DeYoung and Honeycutt 2005), offering powerful new tools for achieving insights into animal behavior and movements (DeYoung 2007). An increasing number of studies have begun to use genetic information to assist large-scale applied management (e.g., Root et al. 2003, Hampton et al. 2004), an analytical approach that is now termed landscape genetics (Manel et al. 2003).

We conducted a series of population genetic analyses aimed at assisting gray fox ORV strategies in western Texas. The specific objective of our study was to estimate the degree and spatial extent of population structuring in the ORV region. If structuring was detected, we would attempt to identify landscape features influencing population structure.

\section{STUDY AREA}

Our study focused on the area inside and around the perimeter of the Texas gray fox ORV zone in west-central Texas. The geographic extent of the ORV zone has varied in geographic extent since its inception in 1996. During study 
collection, the specific area encompassed 33 counties, a geographic area of about $4 \times 10^{5} \mathrm{~km}^{2}$ (Fig. 1). The ORV zone included much of the Edwards Plateau, a semiarid region comprised mostly of rangelands characterized by rocky plains interspersed with hills and steep drainages (Hatch et al. 1990).

\section{METHODS}

\section{DNA Extraction and Amplification}

We obtained tissue biopsies (ear punch or muscle) from gray fox during 2005-2006 (Fig. 1). We trapped or collected gray foxes during evaluations of annual ORV bait dispersion (Sidwa et al. 2005), ongoing research projects, road kills, and wildlife damage management activities. For each tissue sample collected, we recorded corresponding Global Positioning System coordinates of the collection site along with the sex and approximate age (juv or ad). We placed tissues in cryovials containing $1 \mathrm{~mL}$ of $70 \%$ ethanol and maintained them at $-20^{\circ} \mathrm{C}$ until DNA extractions.

We extracted DNA using a commercial kit (DNeasy tissue kit; Qiagen Genomics, Valencia, CA) and used the polymerase chain reaction (PCR) to amplify 5 microsatellite loci (GF-02, GF-07, GF-09, GF-12, and GF-14) from a panel designed for gray fox (Weston et al. 2004). We amplified microsatellite loci in $25-\mu \mathrm{L}$ reaction volumes containing $12.5 \mu \mathrm{L}$ Amplitaq Gold PCR Master Mix (a premixed solution of thermal-stable DNA polymerase, dNTP, $\mathrm{Mg}^{++}$, and buffer; Applied Biosystems, Foster City, CA), 10 picomoles (pmol) each primer, and 10-50 ng DNA. Thermal cycling conditions are described in Weston et al. (2004). We combined the PCR products ( $3 \mu \mathrm{L}$ each reaction) for each individual and applied $1 \mu \mathrm{L}$ of the mixture to a denaturing formamide and size standard mix (Hi-Di Formamide, Rox 500, Applied Biosystems). We then loaded the PCR product mixtures onto an ABI 3130xl DNA sequencer (Applied Biosystems) for separation and detection. We quantified fragment sizes and resolved into multilocus genotypes using GENEMAPPER 4.0 software (Applied Biosystems), followed by visual inspection and verification.

We sequenced a portion of the hypervariable mtDNA control region (Domain I) using primers LGL 283F, 5'TACACTGGTCTTGTAAACC-3', and LGL 1115R, 5' ATGACCCTGAAGAARGAACCAG-3' (Harlin-Cognato et al. 2006). We amplified the control region sequences in 25$\mu \mathrm{L}$ reaction volumes containing $12.5 \mu \mathrm{L}$ Amplitaq Gold PCR Master Mix (Applied Biosystems), 10 pmol of each primer, and 10-50 ng DNA. Reaction conditions consisted of an initial denaturation at $94^{\circ} \mathrm{C}$ for 12 minutes followed by 32 cycles of $94^{\circ} \mathrm{C}$ for 50 seconds, $61^{\circ} \mathrm{C}$ for 60 seconds, $72^{\circ} \mathrm{C}$ for 2 minutes, with a final extension at $72^{\circ} \mathrm{C}$ for 30 minutes. We electrophoresed PCR products on $1 \%$ agarose gels containing ethidium bromide and viewed under ultraviolet light to verify successful amplification. We purified products from successful reactions using an enzymatic method (ExoSAP-IT; USB Corporation, Wilmington, MD), then used the purified products as templates for sequencing reactions using the BigDye Terminator Cycle Sequencing kit v1.1 (Applied Biosystems). We removed unincorporated dye terminators
(DyeEx 2.0 spin kit, Qiagen) and sequenced each sample in both directions on an ABI 3130xl automated DNA sequencer (Applied Biosystems).

\section{Data Analysis}

We performed 3 analyses aimed at quantifying the number of discrete groups and the spatial extent of population structure in the gray fox ORV zone. First, we used the computer program FSTAT 2.9.3 (Goudet 2001) to test for both HardyWeinberg equilibrium and for genetic structure over the entire data set based on $F_{S T}$ (Weir and Cockerham 1984). We tested for significant departure of global $F_{S T}$ from zero by jackknifing over loci, while significance of departure from Hardy-Weinberg expectations was assessed by 1,000 randomizations of alleles among individuals. We performed a locus-by-locus analysis of molecular variance (AMOVA; Weir and Cockerham 1984, Excoffier et al. 1992, Weir 1996) and exact tests of population differentiation using the computer program ARLEQUIN 3.1 (Excoffier et al. 2005), where gray fox samples collected within counties were pooled and each county was treated as a discrete population. We only conducted AMOVA and exact tests among counties with an arbitrary minimum of 13 gray fox samples (aimed at gaining reasonable estimates of allele frequencies). The AMOVA analysis partitions genetic variation among populations (counties) and individuals, while the exact tests of population differentiation test the hypothesis of a random distribution of genotypes among populations. Statistical significance of the AMOVA was assessed by 1,023 permutations of genotypes among counties; statistical significance of the exact tests was assessed with the Markov chain procedure of Guo and Thompson (1992).

Next, we used a Bayesian clustering algorithm (Pritchard et al. 2000) implemented in the computer program STRUCTURE 2.1 (http://pritch.bsd.uchicago.edu/software.html, accessed 31 Aug 2009) to assess the number of discrete genetic clusters $(K)$ present in the ORV zone. The algorithm groups individuals into clusters that minimize Hardy-Weinberg and gametic disequilibrium without regard to the spatial location of the sample, requiring no a priori assumptions about population (cluster) boundaries. We used the admixture model and assumed allele frequencies to be correlated. We performed 100,000 burn-in repetitions (reps) to minimize the effect of the starting configuration, followed by 250,000 reps of data collection. We performed 10 independent runs for each $K$ (assumed no. of genetic clusters) to evaluate consistency of the results. We performed 2-3 additional runs of varying lengths for each $K$ to further evaluate consistency of the results. We used the mean and standard deviation of the estimated log probability of data, $\mathrm{L}(K)$, among runs for the same $K$ to assess the most likely number of unique clusters supported by the data.

Finally, we performed an analysis of spatial autocorrelation to investigate the spatial extent of genetic structure in the ORV zone. Spatial autocorrelation quantifies the degree to which individual genotype frequencies are correlated as a function of the Euclidian geographic distance between pairs of individuals, useful for defining the spatial extent of 
Table 1. Observed $\left(\mathrm{H}_{\mathrm{O}}\right)$ and expected heterozygosity $\left(\mathrm{H}_{\mathrm{E}}\right)$, number of alleles $(k)$, and fixation indices $\left(F_{I S}\right.$ and $\left.F_{S T}\right)$ for 5 microsatellite DNA loci amplified in a gray fox population sampled in west-central Texas, USA, during 2004-2005.

\begin{tabular}{lcccrrrrr}
\hline \multicolumn{1}{c}{ Locus } & $\boldsymbol{n}$ & $\mathbf{H}_{\mathbf{O}}$ & $\mathbf{H}_{\mathrm{E}}$ & $\boldsymbol{k}$ & $\boldsymbol{F}_{\boldsymbol{I S}}$ & $\mathrm{SE}$ & $\boldsymbol{F}_{\boldsymbol{S T}}$ & \multicolumn{1}{c}{ SE } \\
\hline GF-02 & 454 & 0.75 & 0.89 & 23 & 0.177 & $0.020^{*}$ & 0.007 & 0.004 \\
GF-07 & 461 & 0.75 & 0.80 & 17 & 0.053 & 0.035 & -0.002 & 0.004 \\
GF-09 & 457 & 0.87 & 0.85 & 9 & -0.034 & 0.021 & 0.007 \\
GF-12 & 369 & 0.76 & 0.76 & 16 & 0.023 & 0.029 & 0.012 & $0.003^{*}$ \\
GF-14 & 467 & 0.70 & 0.72 & 9 & 0.036 & 0.036 & 0.013 & 0.008 \\
Mean or total & & 0.75 & & 74 & 0.051 & 0.039 & 0.007 & $0.003^{*}$ \\
\hline
\end{tabular}

* 95\% CI does not include zero.

population structuring (Manel et al. 2003). We used Moran's I (Moran 1950, Sokal and Oden 1978) as a measure of autocorrelation because the performance of, and theoretical basis for, Moran's $I$ has been extensively investigated in simulation and empirical studies (Hardy and Vekemans 1999, Epperson 2004). We estimated Moran's I (averaged over loci) for all pairs of individuals separated by distance intervals of $10 \mathrm{~km}$, out to $300 \mathrm{~km}$. We used $10-\mathrm{km}$ intervals to assess autocorrelation on a scale relevant to the width of the annual bait drops in the ORV zone (approx. 16$24 \mathrm{~km}$ ), the area contained by the ORV zone (approx. $300 \mathrm{~km}$ in diam), and the occasional long-distance movements observed in previous studies $(\leq 80 \mathrm{~km})$. We tested the statistical significance (2-sided) of Moran's $I$ for each distance class by comparing the observed value versus a null value derived from 1,000 permutations of individual locations. We estimated standard errors of $I$-values by jackknifing over loci. We performed analyses using the computer program $S_{P A} G_{E} D_{I}$ 1.2 (Hardy and Vekemans 2002).

We assembled, aligned, and edited the mtDNA sequences using the computer program SEQUENCHER 4.5 (Gene Codes, Ann Arbor, MI). We indexed genetic diversity at the haplotype $(H)$ and nucleotide $(\pi)$ level using the computer program DNASP (Rozas et al. 2003). Haplotype diversity is the probability that any 2 randomly sampled haplotypes are different, while $\pi$ is average number of nucleotide differences per site (Nei 1987). We estimated $F_{S T}$ among counties $(\theta$; Weir and Cockerham 1984, Excoffier et al. 1992) as a measure of population structure based on mtDNA haplotypes using the computer program ARLEQUIN 3.1.

\section{RESULTS}

We genotyped 469 adult foxes from the 33 counties at 5 microsatellite loci. Sampled foxes had high levels of genetic diversity, in terms of both observed heterozygosity and number of alleles (Table 1). Locus GF-02 had a slight excess of homozygotes, possibly due to the presence of null or nonamplifying alleles at low frequency. Locus GF-12 was problematic to score at times due to unusual patterns of stutter. Altering PCR conditions improved this somewhat, but there remained cases where it was difficult to reliably make allele size-calls for a second allele. In the cases where a second allele appeared to be present but we could not confidently establish a size-call, we followed a conservative strategy of coding the second allele as missing to distinguish this case from a true homozygote. As a result, fewer complete genotypes were obtained for this locus than the other four (Table 1). We observed slight but statistically significant genetic structure $\left(F_{S T}=0.007\right)$ over the entire data set; $F_{I S}$ was positive but was not statistically different from zero (Table 1 ).

We considered 14 counties for AMOVA and exact tests of differentiation $(n=359$, range $=13-57$, median $/$ county $=$ 20.5). The AMOVA revealed that $94.3 \%$ of genetic variation was contained within individuals, $5.0 \%$ among individuals within counties, and only $0.7 \%$ among counties. The exact tests of differentiation revealed no statistically significant differences among all counties (global $P$-value $>0.79$ ), or for pairwise tests between counties $(P>0.10)$. The STRUCTURE results revealed that the maximal value of $\mathrm{L}(K)$ was attained at $K=1$ (Fig. 2). The $\mathrm{L}(K)$ values decreased for each $K>1$ and became more variable among runs. The proportion of individuals in each inferred cluster for $K>1$ were evenly distributed (e.g., for $K=2$, each cluster contained $50 \%$ of individuals, for $K=3$, each cluster contained 33\% of individuals, etc.). The maximum values of $\mathrm{L}(K)$ never reached a plateau, so there was no need to employ the rate of change metrics recommended by Evanno et al. (2005) for identification of genetic clusters. We concluded that the AMOVA, exact test, and STRUCTURE results supported only a single genetic cluster in the ORV zone.

Statistical power for spatial autocorrelation analyses can be indexed by the total number of alleles $(k)$ multiplied by the number of sampled individuals $(N)$; if the product $(k \times N)$ is at least several thousand, tests for $I$ have sufficient power (Epperson 2005). Thus, our sample of 469 foxes and 74 alleles $(k \times N=34,706)$ provided more than adequate statistical power to detect departures from equilibrium. Indeed, the autocorrelation coefficients revealed weak but statistically

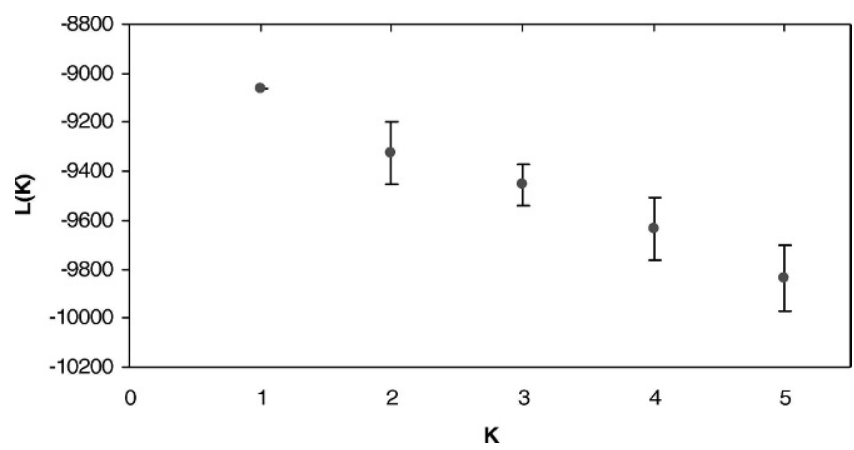

Figure 2. $\log$ probability of data $[\mathrm{L}(K)]$ as a function of $K$ averaged over 10 independent runs for gray fox in west-central Texas, USA, derived using a Bayesian clustering algorithm implemented in the computer program STRUCTURE. The Y-error bars are \pm 1 standard deviation and $K$ is the assumed number of genetic clusters. 
Table 2. Observed and permuted values of spatial autocorrelation coefficients (Moran's $I$ ) averaged over 5 microsatellite loci for 469 gray foxes collected during 2004-2005 in the Texas, USA, oral rabies vaccination zone over 30 10-km distance classes.

\begin{tabular}{|c|c|c|c|c|c|c|c|}
\hline Class $^{\mathrm{a}}$ & No. pairs ${ }^{b}$ & $\%$ & $\mathrm{CV}^{\mathrm{c}}$ & Observed & SE & Permuted & $P$-value ${ }^{\mathrm{d}}$ \\
\hline 10 & 2,155 & 90.4 & 1.12 & 0.021 & 0.010 & $2.2 \times 10^{-6}$ & $<0.001^{* * * * *}$ \\
\hline 20 & 1,443 & 88.3 & 0.87 & 0.013 & 0.004 & $3.0 \times 10^{-3}$ & $0.035^{* *}$ \\
\hline 30 & 2,090 & 94.7 & 0.88 & 0.014 & 0.003 & $-9.3 \times 10^{-5}$ & $0.003^{\text {***** }}$ \\
\hline 40 & 2,335 & 97.9 & 0.71 & -0.002 & 0.006 & $-1.4 \times 10^{-4}$ & 0.628 \\
\hline 50 & 2,559 & 97.0 & 0.67 & 0.002 & 0.003 & $-5.6 \times 10^{-5}$ & 0.588 \\
\hline 60 & 2,089 & 94.9 & 0.80 & 0.010 & 0.005 & $-2.6 \times 10^{-3}$ & $0.055^{*}$ \\
\hline 70 & 1,870 & 97.0 & 0.93 & 0.009 & 0.006 & $-2.0 \times 10^{-4}$ & $0.075^{*}$ \\
\hline 80 & 2,231 & 94.9 & 0.83 & $-3.6 \times 10^{-4}$ & 0.006 & $-1.5 \times 10^{-4}$ & 0.998 \\
\hline 90 & 2,588 & 90.8 & 0.91 & -0.002 & 0.003 & $-5.8 \times 10^{-5}$ & 0.718 \\
\hline 100 & 2,822 & 97.4 & 0.86 & 0.017 & 0.001 & $-1.1 \times 10^{-4}$ & $<0.001^{\text {***** }}$ \\
\hline 110 & 3,468 & 97.4 & 0.79 & $2.4 \times 10^{-4}$ & 0.005 & $-1.7 \times 10^{-4}$ & 0.910 \\
\hline 120 & 4,078 & 96.6 & 0.75 & 0.007 & 0.004 & $-9.6 \times 10^{-5}$ & $0.019^{\text {** }}$ \\
\hline 130 & 4,030 & 99.6 & 0.63 & 0.005 & 0.002 & $-7.2 \times 10^{-5}$ & $0.083^{*}$ \\
\hline 140 & 4,479 & 98.9 & 0.67 & -0.005 & 0.005 & $-2.7 \times 10^{-5}$ & 0.147 \\
\hline 150 & 4,632 & 99.1 & 0.72 & -0.001 & 0.006 & $-5.3 \times 10^{-5}$ & 0.654 \\
\hline 160 & 3,975 & 98.5 & 0.70 & -0.001 & 0.004 & $-1.9 \times 10^{-4}$ & 0.826 \\
\hline 170 & 4,082 & 99.6 & 0.65 & 0.003 & 0.002 & $-2.7 \times 10^{-5}$ & 0.363 \\
\hline 180 & 3,827 & 100 & 0.62 & 0.003 & 0.004 & $-9.2 \times 10^{-5}$ & 0.319 \\
\hline 190 & 4,727 & 100 & 0.68 & -0.002 & 0.002 & $-5.6 \times 10^{-6}$ & 0.562 \\
\hline 200 & 3,844 & 99.8 & 0.64 & -0.004 & 0.004 & $3.6 \times 10^{-5}$ & 0.307 \\
\hline 210 & 4,038 & 100 & 0.55 & 0.001 & 0.004 & $1.8 \times 10^{-4}$ & 0.786 \\
\hline 220 & 4,049 & 100 & 0.63 & -0.005 & 0.003 & $3.3 \times 10^{-5}$ & 0.147 \\
\hline 230 & 4,774 & 100 & 0.58 & -0.006 & 0.003 & $-2.6 \times 10^{-4}$ & $0.043^{\text {*k }}$ \\
\hline 240 & 4,466 & 99.6 & 0.61 & -0.006 & 0.005 & $-1.5 \times 10^{-5}$ & $0.043^{\text {** }}$ \\
\hline 250 & 4,362 & 99.6 & 0.63 & -0.002 & 0.005 & $-2.2 \times 10^{-5}$ & 0.588 \\
\hline 260 & 3,683 & 94.9 & 0.67 & -0.003 & 0.002 & $-1.4 \times 10^{-4}$ & 0.425 \\
\hline 270 & 3,480 & 94.5 & 0.65 & -0.002 & 0.003 & $1.1 \times 10^{-4}$ & 0.614 \\
\hline 280 & 2,987 & 92.1 & 0.73 & -0.008 & 0.004 & $3.4 \times 10^{-5}$ & $0.033^{\text {*** }}$ \\
\hline 290 & 2,594 & 91.3 & 0.80 & 0.004 & 0.010 & $-2.6 \times 10^{-4}$ & 0.353 \\
\hline 300 & 2,100 & 86.6 & 0.93 & 0.001 & 0.005 & $-2.8 \times 10^{-4}$ & 0.696 \\
\hline
\end{tabular}

${ }^{a}$ Upper distance bound $(\mathrm{km})$.

${ }^{\mathrm{b}}$ No. of pairwise comparisons within each interval.

c Percentage of sampled individuals participating at least once in the interval and the coefficient of variation of the no. of times each individual is represented.

d Two-sided $P$-values: * $P<0.1$; ** $P<0.05$; **** $P<0.01$.

significant positive autocorrelation over the first $310-\mathrm{km}$ distance classes (Table 2). Five additional statistically significant, positive $I$-values spanned distance classes $60-130 \mathrm{~km}$, with negative correlations observed at greater spatial distance classes (Table 2), suggesting an isolation by distance pattern.

We sequenced 401 base pairs (397 base pairs excluding alignment gaps) for 25 adult female gray foxes. We resolved the sequences into 7 haplotypes; $H$ and $\pi$ were 0.67 (SD = $0.10)$ and $0.007(\mathrm{SD}=0.003)$, respectively. Tests of genetic structure among haplotypes revealed no statistically significant structure $\left(F_{S T}=-0.13, P=0.62\right)$ among counties in the ORV zone. No geographic pattern to the distribution of mtDNA haplotypes was apparent upon visual inspection.

\section{DISCUSSION}

We detected only weak genetic structure over the spatially extensive gray fox ORV zone in Texas, a conclusion substantiated by several different analytical approaches using both microsatellite and mtDNA markers. There was no evidence for unique genetic clusters, which implies that landscape features have a minimal effect on gray fox population structure in the region. At the very least, no habitat features affected population structuring to the extent that they could be useful to the ORV management. Thus, we were unable to satisfy one of the main goals of the study, the identification of landscape features affecting gray fox population structure that could be used in management. Instead, gray foxes appeared to be weakly structured as a function of geographic distance between individuals. The weak structuring followed an isolation by distance pattern, where greater than expected autocorrelation was observed at proximate distance classes, and lower than expected observed at extreme distance classes. Our autocorrelation values were comparable to those observed in fine-scale studies of dispersal in plants and small mammals, where distance intervals were measured in tens of meters (e.g., Marquardt and Epperson 2004, Walter and Epperson 2004, Peakall et al. 2005). Although the autocorrelation coefficients appeared low, they were actually quite surprising for distance intervals measured in tens of kilometers and corresponded to theoretical expectations for species with high dispersal; simulation studies indicate that Moran's Ivalues in the range of $0.03-0.06$ and $0.0-0.02$ for the first distance category in a correlogram reflected Wright's (1946) neighborhood sizes of $100-250$ and $>250$ individuals, respectively (Epperson 2003). Thus, the autocorrelation analyses strongly suggested that population structure in the gray fox ORV zone extended to $\leq 30 \mathrm{~km}$, and possibly farther. A simple and conservative interpretation of the results would be that gray fox populations within $30 \mathrm{~km}$ are genetically non-independent (Diniz-Filho and Telles 2002). 
Comparable studies of gray fox population structure have not been reported from other parts of the species' range, with the exception of congeneric island fox (U. littoralis) in the Channel Islands of California, USA, where foxes display dramatic population genetic structuring among islands due to restricted over-water dispersal (Goldstein et al. 1999). Studies of widely distributed species of carnivores have revealed that long-distance dispersal can result in weak genetic structuring at spatial scales many times larger than the gray fox ORV zone (Schwartz et al. 2002). In many canid and felid species, structuring at such large spatial scales is often a function of distinct habitat changes (Geffen et al. 2004), presence of dispersal corridors (Ernest et al. 2003, Geffen et al. 2007), or landscape location (e.g., core vs. peripheral populations; Schwartz et al. 2003). Although the region was intersected by United States interstate highways 10 and 20, neither presented the combination of automobile traffic volume or physical barriers to animal movements observed to reduce gene flow in medium-sized carnivores (Riley et al. 2006).

At the landscape scale, Texas gray fox were continuously distributed, with no discernable gaps in populations. It is likely that the weak genetic structure and pattern of spatial autocorrelation that we observed in the gray fox ORV zone were the result of high rates of dispersal. The western Texas landscape apparently presented no physical barriers to gray fox movements. The genetic data were consistent with recent field observations derived from radiotelemetry and tag returns, which have indicated that gray foxes in the ORV zone may move $>20 \mathrm{~km}$ from their initial capture site (B. Mesenbrink, USDA, Wildlife Services, National Wildlife Research Center, unpublished data). Historical reports also note occasional long-distance $(\leq 80 \mathrm{~km})$ movements in the eastern United States (e.g., Sheldon 1953). Our data suggested that long-distance movements in Texas gray fox (on the order of tens of kilometers) may be more common than previously suspected.

A high rate of dispersal appears a likely explanation for the pattern of population structuring observed in the gray fox ORV zone. Unfortunately, we were unable to perform focused tests for sex-bias in dispersal based on differences in $F_{S T}$ and corrected assignment indices (e.g., vAIc; Goudet et al. 2002). This was because simulated data sets suggest that statistical power for the dispersal tests is not expected to be high if the number of microsatellite loci is $<8$ and if the dispersal bias is not pronounced (e.g., $<80: 20$; Goudet et al. 2002). When fixation statistics over the entire data set were compared for biparentally inherited microsatellite markers and maternally inherited mtDNA sequence data, there was little evidence for dispersal bias; fixation indices based on mtDNA did not differ from zero, and only a slight departure was observed from microsatellite markers. We can only conclude that we did not detect firm evidence for sex bias in dispersal in our data set. Further investigation is required to fully establish the existence or prevalence of sexbiased dispersal in gray fox from this region of Texas. Additional hypotheses regarding dispersal that merit investigation include determining if evidence exists for joint dispersal after pair formation or if movements are variable depending on availability of territories or resources.

\section{MANAGEMENT IMPLICATIONS}

Gray fox populations appeared weakly structured and genetically non-independent across a broad $(\geq 30-\mathrm{km})$ geographic extent, suggesting high rates of movement or dispersal. Thus, a population (assuming a $30-\mathrm{km}$ diam) could conservatively span approximately $707 \mathrm{~km}^{2}$, and perhaps farther. Therefore, the historical $16-\mathrm{km}$ to $24-\mathrm{km}$ wide ORV zone barrier (Sidwa et al. 2005) may be too narrow to contain the TF rabies epizootic. Although rabies-positive gray fox have been periodically found outside of the ORV zone, it is uncertain if gray fox incubating rabies virus have actually breached the ORV zone. Plausible alternative hypotheses for the occurrence of rabid individuals outside the ORV zone include persistent, low-level enzootic rabies outside of this zone or interspecific trafficking of the virus. Neither has been detected to date during intensive monitoring following the annual bait distribution campaigns, but these alternatives cannot be conclusively ruled out. Nevertheless, based on our data, we conclude that a spatially extensive ORV zone would be prudent and may in fact be necessary for the effective control of gray fox rabies in Texas. The ORV zone has been expanded in recent years, in part based on preliminary data derived from this study; we recommend that ORV zones for gray fox continue to be managed as spatially extensive. The specific means chosen to implement and maintain a wider ORV zone will ultimately depend upon the resources available and the priorities of the program (e.g., keeping rabies from areas of dense human populations, interspecific variant transmission, etc.). Nonetheless, the width of gray fox ORV zones may be critical to achieve the long-term goal of eliminating the TF variant from the United States.

Managers have begun to recognize that the efficiency and effectiveness of management efforts can be improved through exploiting (Hampton et al. 2004, Robertson and Gemmell 2004) or minimizing population structuring (Epps et al. 2007). At the landscape scale, management units that are defined too conservatively result in wasted effort, whereas failure to control the entire local population may render management ineffective. In this case, the main useful information derived was the detection of weak structure at the landscape scale and the estimation of its spatial extent. This study serves as an example of how genetic tools can assist and focus large-scale wildlife management programs.

\section{ACKNOWLEDGMENTS}

We are indebted and offer our sincere thanks to the Texas Department of State Health Services and Texas Wildlife Services for aid with sample collection and logistical assistance, especially B. Sims, J. Sandoval, E. Miles, J. Dorsett, and M. Mapston. In addition, we express our gratitude to the many private and public land stewards who have graciously given access to their lands to conduct this work. This study would not have been possible without the assistance of a great number of individuals from the aforementioned institutions. Funding for this work was provided by the United States 
Department of Agriculture, Animal Plant Health Inspection Service, Wildlife Services National Wildlife Research Center and the Jack Berryman Institute. A. Zamorano was supported by a National Science Foundation Undergraduate Mentoring in Environmental Biology program for promoting undergraduate student research. This is contribution 2009-118 of the Caesar Kleberg Wildlife Research Institute.

\section{LITERATURE CITED}

Chamberlain, M. J., and B. D. Leopold. 2000. Spatial use patterns, seasonal habitat selection, and interaction among adult gray foxes in Mississippi. Journal of Wildlife Management 64:742-751.

Childs, J. E., A. T. Curns, M. E. Dey, L. A. Real, I. Feinstein, O. N. Bjornstad, and J. W. Krebs. 2000. Predicting the local dynamics of epizootic rabies among raccoons in the United States. Proceedings of the National Academy of Sciences of the USA 97:13666-13671.

Childs, J. E., A. T. Curns, M. E. Dey, L. A. Real, C. E. Rupprecht, and J. W. Krebs. 2001. Rabies epizootics among raccoons vary along a NorthSouth gradient in the Eastern United States. Vector Borne and Zoonotic Diseases 1:253-267.

DeYoung, R. W. 2007. Genetics and applied management: using genetic methods to solve emerging wildlife management problems. Pages 315334 in T. E. Fulbright and D. G. Hewitt, editors. Frontiers in wildlife science: linking ecological theory and management applications. CRC Press, Boca Raton, Florida, USA.

DeYoung, R. W., and R. L. Honeycutt. 2005. The molecular toolbox: genetic techniques in wildlife ecology and management. Journal of Wildlife Management 69:1362-1384.

Diniz-Filho, J. A. F., and M. P. D. Telles. 2002. Spatial autocorrelation analysis and the identification of operational units for conservation in continuous populations. Conservation Biology 16:924-935.

Epperson, B. K. 2003. Geographical genetics. Monographs in population biology 38. Princeton University Press, Princeton, New Jersey, USA.

Epperson, B. K. 2004. Multilocus estimation of genetic structure within populations. Theoretical Population Biology 65:227-237.

Epperson, B. K. 2005. Estimating dispersal from short-distance spatial autocorrelation. Heredity 95:7-15.

Epps, C. W., J. D. Wehausen, V. C. Bleich, S. G. Torres, and J. S. Brashares. 2007. Optimizing dispersal and corridor models using landscape genetics. Journal of Applied Ecology 44:714-724.

Ernest, H. B., W. M. Boyce, V. C. Bleich, B. May, S. J. Stiver, and S. G. Torres. 2003. Genetic structure of mountain lion (Puma concolor) populations in California. Conservation Genetics 4:353-366.

Evanno, G., S. Regnaut, and J. Goudet. 2005. Detecting the number of clusters of individuals using the software STRUCTURE: a simulation study. Molecular Ecology 14:2611-2620.

Excoffier, L., G. Laval, and S. Schneider. 2005. Arlequin version 3.0: an integrated software package for population genetics data analysis. Evolutionary Bioinformatics Online 1:47-50.

Excoffier, L., P. Smouse, and J. Quattro. 1992. Analysis of molecular variance inferred from metric distances among DNA haplotypes: application to human mitochondrial DNA restriction data. Genetics 131:479-491.

Fox, J. P., L. Elveback, W. Scott, L. Gatewood, and E. Ackerman. 1995. Herd immunity: basic concept and relevance to public health immunization practices. American Journal of Epidemiology 141:187-197.

Geffen, E., M. J. Anderson, and R. K. Wayne. 2004. Climate and habitat barriers to dispersal in the highly mobile grey wolf. Molecular Ecology 13:2481-2490.

Geffen, E., S. Waidy, A. Love, D. Angerbjörn, C. Vila, P. Hersteinsson, E. Fuglei, P. A. White, M. Goltsman, C. M. O. Kapel, and R. K. Wayne. 2007. Sea ice occurrence predicts genetic isolation in the Arctic fox. Molecular Ecology 16:4241-4255.

Goldstein, D. B., G. W. Roemer, D. A. Smith, D. E. Reich, A. Bergman, and R. K. Wayne. 1999. The use of microsatellite variation to infer population structure and demographic history in a natural model system. Genetics 151:797-801.

Goudet, J. 2001. FSTAT, a program to estimate and test gene diversities and fixation indices (version 2.9.3). <http://www.unil.ch/izea/softwares/ fstat.html>. Accessed 18 Jul 2008.
Goudet, J., N. Perrin, and P. Waser. 2002. Tests for sex-biased dispersal using bi-parentally inherited genetic markers. Molecular Ecology 11:1103-1114.

Guo, S., and E. Thompson. 1992. Performing the exact test of HardyWeinberg proportion for multiple alleles. Biometrics 48:361-372.

Hampton, J. O., P. B. S. Spencer, D. L. Alpers, L. E. Twigg, A. P. Woolnough, J. Doust, T. Higgs, and J. Pluske. 2004. Molecular techniques, wildlife management and the importance of genetic population structure and dispersal: a case study with feral pigs. Journal of Applied Ecology 41:735-743.

Hardy, O. J., and X. Vekemans. 1999. Isolation by distance in a continuous population: reconciliation between spatial autocorrelation and population genetics models. Heredity 83:145-154.

Hardy, O. J., and X. Vekemans. 2002. SPAGeDi: a versatile computer program to analyse spatial genetic structure at the individual or population levels. Molecular Ecology Notes 2:618.

Harlin-Cognato, A., J. W. Bickham, T. R. Loughlin, and R. L. Honeycutt. 2006. Glacial refugia and the phylogeography of Steller's sea lion (Eumatopias jubatus) in the North Pacific. Journal of Evolutionary Biology 19:955-969.

Hatch, S. L., K. N. Gandhi, and L. E. Brown. 1990. Checklist of the vascular plants of Texas. Texas A\&M University Press, College Station, USA.

Krebs, J. W., E. J. Mandel, D. L. Swerdlow, and C. E. Rupprecht. 2005. Rabies surveillance in the United States during 2004. Journal of the American Veterinary Association 227:1912-1924.

MacDonald, D. W., and C. Sillero-Zubiri. 2004. Dramatis personae. Pages 3-38 in D. W. MacDonald and C. Sillero-Zubiri, editors. Biology and conservation of wild canids. Oxford University Press, Oxford, United Kingdom.

Manel, S., M. K. Schwartz, G. Luikart, and P. Taberlet. 2003. Landscape genetics: combining landscape ecology and population genetics. Trends in Ecology and Evolution 18:189-197.

Marquardt, P. E., and B. K. Epperson. 2004. Spatial and population genetic structure of microsatellites in white pine. Molecular Ecology 13:3305-3315.

Moran, P. A. P. 1950. Notes on continuous stochastic phenomena. Biometrika 37:17-23.

Nei, M. 1987. Molecular evolutionary genetics. Columbia University Press, New York, New York, USA.

Peakall, R., M. Ruibal, and D. B. Lindenmayer. 2005. Spatial autocorrelation analysis offers new insights into gene flow in the Australian bush rat, Rattus fuscipes. Evolution 57:1182-1195.

Pritchard, J. K., M. Stephens, and P. Donnelly. 2000. Inference of population structure using multilocus genotype data. Genetics 155:945-959.

Real, L. A., C. Russell, L. Waller, D. Smith, and J. Childs. 2005. Spatial dynamics and molecular ecology of North American rabies. Journal of Heredity 96:1-8.

Riley, S. P., J. P. Pollinger, R. M. Sauvajot, E. C. York, C. Bromley, T. K. Fuller, and R. K. Wayne. 2006. A southern California freeway is a physical and social barrier to gene flow in carnivores. Molecular Ecology 15:1733-1741.

Robertson, B. C., and N. J. Gemmell. 2004. Defining eradication units to control invasive pests. Journal of Applied Ecology 41:1042-1048.

Root, J. J., W. C. Black, IV, C. H. Calisher, K. R. Wilson, R. S. Mackie, T. Schountz, J. N. Mills, and B. J. Beaty. 2003. Analyses of gene flow among populations of deer mice (Peromyscus maniculatus) at sites near hantavirus pulmonary syndrome case-patient residences. Journal of Wildlife Diseases 39:287-298.

Rozas, J., J. C. Sánchez-DelBarrio, X. Messeguer, and R. Rozas. 2003. DnaSP, DNA polymorphism analyses by the coalescent and other methods. Bioinformatics 19:2496-2497.

Schmidly, D. J. 1994. The mammals of Texas. Revised edition. University of Texas Press, Austin, USA.

Schwartz, M. K., L. S. Mills, K. S. McKelvey, L. F. Ruggiero, and F. W. Allendorf. 2002. DNA reveals high dispersal synchronizing the population dynamics of Canada lynx. Nature 415:520-522.

Schwartz, M. K., L. S. Mills, Y. Ortega, L. F. Ruggiero, and F. W Allendorf. 2003. Landscape location affects genetic variation of Canada lynx (Lynx canadensis). Molecular Ecology 12:1807-1816.

Sheldon, W. G. 1953. Returns on banded red and gray foxes in New York state. Journal of Mammalogy 34:125-126.

Sidwa, T. J., P. J. Wilson, G. M. Moore, E. H. Oertil, B. N. Hicks, R. E. Rohde, and D. H. Johnston. 2005. Evaluation of oral rabies vaccination 
programs for control of rabies epizootics in coyotes and gray foxes: 19952003. Journal of the American Veterinary Medical Association 227:785-792.

Smith, D. L., B. Lucey, L. A. Waller, J. E. Childs, and L. A. Real. 2002. Predicting the spatial dynamics of rabies epidemics on heterogeneous landscapes. Proceedings of the National Academy of Sciences of the USA 99:3668-3672.

Sokal, R. R., and N. L. Oden. 1978. Spatial autocorrelation in biology. 1. Methodology. Biological Journal of the Linnean Society 10:229-249.

Texas Department of Health [presently Texas Department of State Health Services]. 2003. Rabies in Texas: a historical perspective. Texas Department of Health, Austin, USA. < http://www.dshs.state.tx.us/idcu/ disease/rabies/history/historyInTexas.pdf>. Accessed 22 May 2007.

Trapp, G. R., and D. L. Hallberg. 1975. Ecology of the gray fox (Urocyon cinereoargenteus): a review. Pages 164-178 in M. W. Fox, editor. The wild canids: their systematics, behavioral ecology and evolution. Van Nostrand Reinhold, New York, New York, USA.

United States Department of Agriculture [USDA]. 2001. Wildlife Services rabies management national report, fiscal year 2001. United States Department of Agriculture, Animal and Plant Health Inspection Service, Wildlife Services, Concord, New Hampshire, USA.
United States Department of Agriculture [USDA]. 2002. Cooperative Rabies Management Program national report 2002. United States Department of Agriculture, Animal and Plant Health Inspection Service, Wildlife Services, Concord, New Hampshire, USA.

Walter, R., and B. K. Epperson. 2004. Microsatellite analysis of spatial structure among seedlings in populations of Pinus strobus (Pinaceae). American Journal of Botany 91:549-557.

Weir, B. S. 1996. Genetic data analysis II: methods for discrete population genetic data. Sinauer, Sunderland, Massachusetts, USA.

Weir, B. S., and C. C. Cockerham. 1984. Estimating F-statistics for the analysis of population structure. Evolution 38:1358-1370.

Weston, J. L., N. A. Schable, and T. C. Glenn. 2004. Characterization of six microsatellite primers for the grey fox (Urocyon cinereoargenteus). Molecular Ecology Notes 4:503-505.

Wright, S. 1946. Isolation by distance under diverse systems of mating. Genetics 31:39-59.

Associate Editor: Latch. 